\title{
Making College Count: An Examination of Quantitative Reasoning Activities in Higher Education
}

Louis M. Rocconi

Indiana University Bloomington, Irocconi@utk.edu

Amber D. Lambert

Indiana University Bloomington, adlamber@indiana.edu

Alexander C. McCormick

Indiana University Bloomington, amcc@indiana.edu

Shimon A. Sarraf

Indiana University Bloomington, ssarraf@indiana.edu

Follow this and additional works at: https://digitalcommons.usf.edu/numeracy

Part of the Educational Assessment, Evaluation, and Research Commons

\section{Recommended Citation}

Rocconi, Louis M., Amber D. Lambert, Alexander C. McCormick, and Shimon A. Sarraf. "Making College Count: An Examination of Quantitative Reasoning Activities in Higher Education." Numeracy 6, Iss. 2 (2013): Article 10. DOI: http://dx.doi.org/10.5038/1936-4660.6.2.10 


\title{
Making College Count: An Examination of Quantitative Reasoning Activities in Higher Education
}

\begin{abstract}
Findings from national studies along with more frequent calls from those who employ college graduates suggest an urgent need for colleges and universities to increase opportunities for students to develop quantitative reasoning (QR) skills. To address this issue, the current study examines the relationship between the frequency of QR activities during college and student and institutional characteristics, as well as whether students at institutions with an emphasis on QR (at least one QR course requirement for all students) report more QR activity. Results show that gender, race-ethnicity, major, full-time status, firstgeneration status, age, institutional enrollment size, and institutional control are related to the frequency of QR activities. Findings also suggest that such activities are indeed more common among institutions that emphasize QR.
\end{abstract}

\section{Keywords}

quantitative reasoning, quantitative literacy, student development

\section{Creative Commons License}

\section{c) (7) (8)}

This work is licensed under a Creative Commons Attribution-Noncommercial 4.0 License

\section{Cover Page Footnote}

Louis M. Rocconi is an assistant research scientist at the Indiana University Center for Postsecondary

Research. He provides analytic support for the National Survey of Student Engagement and the Law School Survey of Student Engagement. His research interests include methodological issues in educational research, student growth and development in college, and students' use of quantitative reasoning activities.

Amber D. Lambert is an assistant research scientist at the Indiana University Center for Postsecondary Research. In her role as a research analyst, Amber provides analytic support to several large survey research projects, including the Strategic National Arts Alumni Project and the National Survey of Student Engagement. Her research interests include gender issues in higher education, arts education, engineering education, creativity, and quantitative reasoning.

Alexander C. McCormick is an associate professor of educational leadership and policy studies at Indiana University Bloomington, where he teaches in the Higher Education and Student Affairs Program. He also directs the National Survey of Student Engagement, which seeks to advance the national conversation on college quality while providing colleges and universities with diagnostic, actionable information on the extent to which students engage in educationally purposeful activities.

Shimon A. Sarraf is the Assistant Director for Survey Operations \& Project Services at the National Survey of Student Engagement. Besides helping institutions administer NSSE, he conducts research on various topics related to college student development and survey methodology. 


\section{Introduction}

In an increasingly data-driven world we must routinely use and make sense of quantitative information. The quantitative demands imposed by today's society and in the modern workforce are great and are growing (Steen 2001; Madison and Steen 2008; Madison 2009; Dingman and Madison 2010). Today's job market demands quantitative skills from college graduates, regardless of career (RiveraBatiz 1992; Steen 2001; Dingman and Madison 2011). In addition, quantitative literacy is increasingly important for effective democratic participation (Steen 2001). The American public faces a multitude of quantitative information both in

the workplace and in everyday life. As such, there is a growing consensus that to be able to function in today's society, people need to be quantitatively literate, that is, they need to be able to process and understand quantitative information (Shavelson 2008).

The concept of quantitative literacy (QL) grew out of a call for workers to be better and more-informed users of quantitative information (Wilkins 2000). A person's functional literacy in the $21^{\text {st }}$ century, as championed by Steen (1997), must extend beyond reading and writing to include the ability to understand and use quantitative information. Well-informed and productive citizens must be able to use and understand the wealth of quantitative information available today in the workplace, on TV, on the Internet, in newspapers, and in everyday life. QL transcends the mere ability to perform mathematical computations to include a deeper understanding of quantitative data. QL includes an everyday understanding of mathematics; in other words, the ability to use numerical, statistical, and graphical information in everyday life (Steen 1997, 2001; Wilkins 2000, 2010). Wilkins (2000) describes a quantitatively literate person as one who possesses "a functional knowledge of mathematical content, the ability to reason mathematically, a recognition of the societal impact and utility of mathematics, and a positive disposition towards mathematics” (p. 406). Similarly, Steen (1997) described QL as a "walking around" knowledge of mathematics or the ability to handle quantitative information that one might encounter in everyday life. Beyond the need to use and interpret quantitative information in everyday life, a rich understanding of quantitative information is also a necessity in the workplace. Employees at all levels and in all fields must be able to identify problems, analyze and interpret information, and make decisions based on that information (Wilkins 2000). 
Noting the importance of developing QL, the Mathematical Association of America (Madison and Steen 2008), the National Research Council (1989), National Council of Teachers of Mathematics (1989, 2000), the Association of American Colleges and Universities (AAC\&U) (2007, 2009), and the National Committee on Excellence in Education (1983) have all emphasized the need for students to learn to apply mathematics to everyday situations and to function in a quantitative society.

Despite these arguments for the increasing importance of QL, the 2003 National Assessment of Adult Literacy (NAAL) found no significant gains between 1992 and 2003 in QL at any education level (Kutner et al. 2007). It also found significant gaps in QL between men and women and between racial-ethnic groups. Men had higher average QL than women in both 1992 and 2003, but the gap has narrowed; White and Asian/Pacific Islander adults had higher QL than Black and Hispanic adults. The report further found that only about one-third of college graduates demonstrated proficiency in QL.

Findings from the NAAL, the importance of quantitative literacy to both citizenship and the workplace, and the increased need to understand, reason, and make decisions based on quantitative information point to the need for colleges and universities to enhance students' ability to make sense of, effectively use, and be knowledgeable consumers of quantitative information (Taylor 2008; Dingman and Madison 2010, 2011). Reflecting these concerns, the AAC\&U (2007) includes QL in its list of "essential learning outcomes" (p. 12), and its VALUE (Valid Assessment of Learning in Undergraduate Education) rubric (2009) describes individuals with QL skills as those who "possess the ability to reason and solve quantitative problems from a wide variety of contexts and everyday situations” (p. 1).

These developments suggest an urgent need for colleges and universities to assess the opportunities they provide to students in all majors to develop facility with quantitative reasoning (QR). (For the purposes of this paper, we define QR activities and skills as those performed and developed in order to become a quantitatively literate person.) Indeed, a number of colleges and universities have instituted programs designed to ensure that graduates develop QR skills regardless of major (Gillman 2006).

Despite the importance of developing QR abilities, we could not find any existing research that examined students' use of QR activities in college. The current study addresses this gap in the research by examining the prevalence of key QR activities among students attending bachelor's degree-granting colleges and universities. Because QR activities in college have received little scholarly examination, this exploratory study investigates the relationship between QR activities and various student and institutional characteristics and suggests avenues of further inquiry. 


\section{Background: National Survey of Student Engagement}

Student engagement is a key concept in higher education literature. Although scholars have used different terminology to describe student engagement, their views all reflect the premise that learning in college is related to the way students spend their time and energy in both formal learning settings such as classrooms and informal learning activities that are related to and reinforce their formal counterparts (McCormick et al. 2013). Student engagement and related concepts have been used in various forms in the works of Astin (1984), Pace (1979), Kuh (2001, 2009; Kuh et al. 1991), and Pascarella (1985). Decades of research at the undergraduate level show that students benefit from college when their efforts are directed at learning-centered activities both inside and outside of the classroom (see Pace 1979; Pascarella and Terenzini 1991, 2005; Astin 1993; Pike et al. 2003). The premise of engagement is simple: what students do matters, and the more they engage in educationally purposeful activities, the greater the likelihood of learning and development.

In an effort to leverage these ideas to inform the assessment and improvement of undergraduate education, the National Survey of Student Engagement (NSSE) was launched in 2000. NSSE surveys first-year and senior students at bachelor's degree-granting colleges and universities in order to assess the extent to which an institution's students are exposed to and participate in effective educational practices. Centralized, standardized sampling and administration procedures ensure the comparability of results among participating institutions. Institutions must elect to participate in NSSE, and each year a large and diverse group of institutions do so, with the number of participating institutions each year numbering from 600 to nearly 800. Over the life of the project, more than 1,500 colleges and universities in the United States and Canada have participated. Although participation is voluntary, the mix of participating institutions reflects the diversity of U.S. higher education with respect to size, public or private control, and Carnegie Classification.

In each NSSE administration, several sets of experimental items are asked of different subsets of respondents. In 2011, one of these sets focused on QR because NSSE staff had identified QR/QL as an untapped content area in need of further investigation. Calls from major higher education associations about the importance for developing QR skills among college students and its centrality to general education outcomes were influential to NSSE's decision making (AAC\&U 2007, 2009; Schneider 2004). In addition, arguments put forth by members of the QL community related to the importance of QR skills in the workplace and civic life were also persuasive (Steen 2001; Madison and Steen 2003). Findings from the experimental items, including those reported in this 
paper, led to the incorporation of a reduced set in a major update of the NSSE survey that took effect in 2013.

\section{Research Questions}

The purpose of this study is to explore the relationship between the frequency of college students' QR activities and student and institutional characteristics, as well as to investigate whether students at institutions with an avowed emphasis on $\mathrm{QR}$ in fact report more QR activity. The following research questions guide this study:

1. What is the relationship between student and institutional characteristics and the frequency of students' participation in QR activities?

2. Do the influences on students' frequency of QR activities differ for STEM and non-STEM majors?

3. Do students at institutions with an emphasis on QR report more frequent QR activity?

We pose these questions as a starting point to investigate students' engagement in QR activities in college. Since virtually no research has explored the opportunities college and universities offer students to develop their QR abilities, this research will serve as a first step in advancing our understanding of the role that higher education plays in developing QR and QL among college graduates.

\section{Methods}

\section{Sample}

Data for this study come from the 2011 administration of NSSE. In a set of experimental questions, students reported on the frequency of various uses of numerical, statistical, and graphical information (see Table 1). Thirty-three out of

\section{Table 1}

NSSE 2011 Experimental Items on Quantitative Reasoning



1. Reached conclusions based on your own analysis of numbers, graphs, or statistics

2. Used numbers, graphs, or statistics to help analyze a contemporary or historical issue (poverty, climate change, etc.)

3. Explained in writing the meaning of numbers, graphs, or statistics

4. Analyzed others' conclusions by using numbers, graphs, or statistics 
the 683 U.S. institutions that participated in NSSE in 2011 were selected to receive the QR questions. We intentionally sampled eight of these institutions to receive the additional QR items because they had been identified by Steen (2007) on his quantitative literacy Web site and/or featured in Current Practices in Quantitative Literacy (Gillman 2006). The analysis sample consisted of more than 13,000 first-year and senior students enrolled at 25 four-year institutions who had complete data on the variables described below. ${ }^{1}$ In addition to the original eight institutions, two more were identified as emphasizing QR (see Variables section for more details).

A comparison of the sample institutions and respondents to all baccalaureate-granting U.S. institutions and their students is presented in Table 2. Over half of the students in the sample attended research universities with very

Table 2

Profile of Institutions and Students from Sample and All Baccalaureate-granting U.S. Institutions ${ }^{\mathrm{a}}$

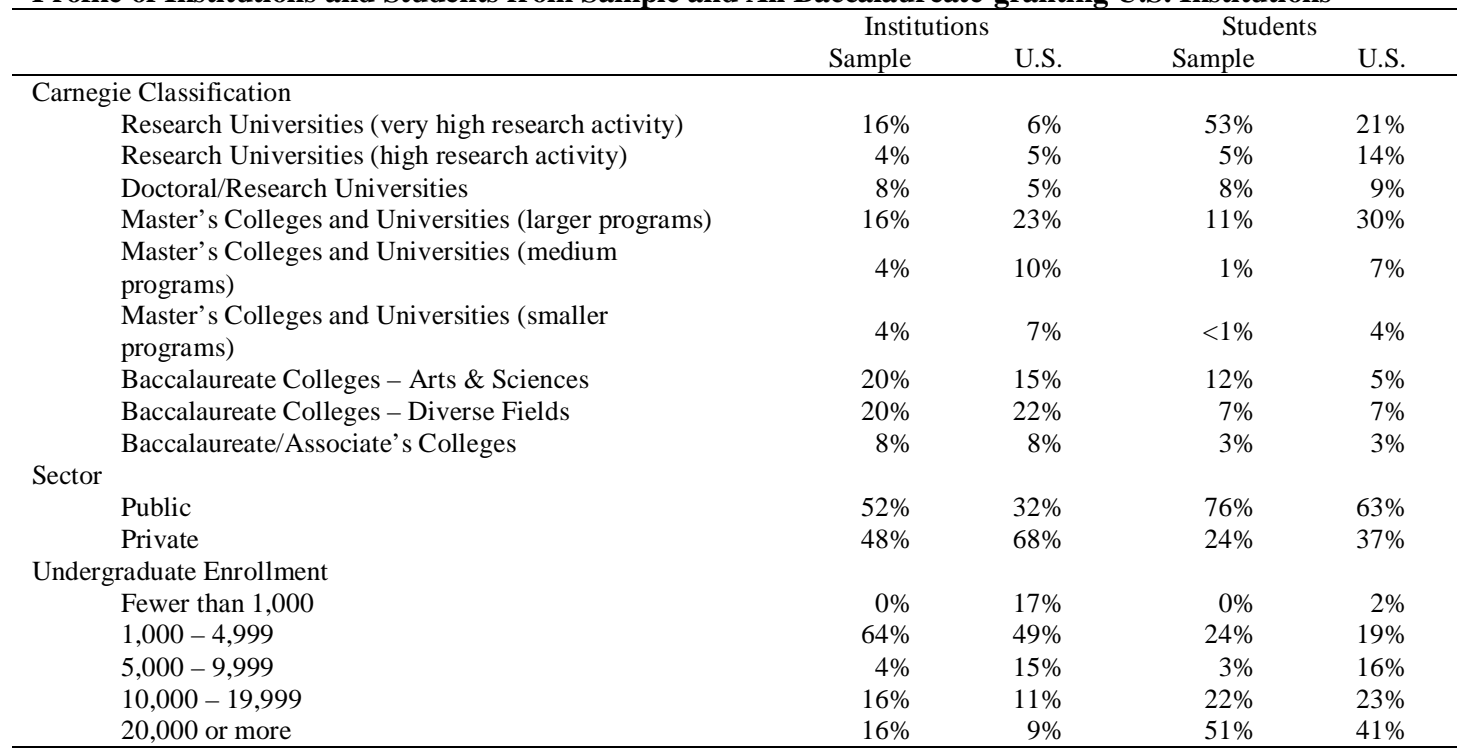

${ }^{a}$ Percentages are based on 2010-2011 IPEDS data for students at institutions that belong to one of the nine Carnegie classes in the table. Totals may not sum to $100 \%$ due to rounding.

\footnotetext{
${ }^{1}$ We used list-wise deletion of missing data, causing the exclusion of about $30 \%$ of students and eight institutions in the full dataset. Nearly all of the loss (about 99\%) was due to cases lacking SAT or ACT scores. Despite this, the composition of the analysis sample closely resembled that of the entire dataset in terms of gender, race-ethnicity, first-generation status, distance education status, and proportion of STEM majors. Because of the loss of SAT/ACT information, the analysis sample was younger than the full dataset (average age of 20.3 and 21.8 years, respectively), and contained more full-time students (97\% vs. 94\%), and fewer transfer students (11\% vs. $21 \%$ ) than the full dataset.
} 
high research activity, compared with a little more than one-fifth of the national profile of students. In addition, the sample included a higher percentage of students at baccalaureate arts and science institutions and fewer students at master's level institutions than the national profile. While the sample does not mirror the national sample exactly, this study does not seek to generalize to all U.S. students.

The sample was approximately $61 \%$ female; $97 \%$ were enrolled full-time; $33 \%$ were first-generation students (neither parent holds a bachelor's degree or higher); and $1 \%$ were taking all their courses entirely online. About $8 \%$ classified themselves as African-American, $6 \%$ as Asian, $74 \%$ as Caucasian, $6 \%$ as Hispanic, with the rest classifying themselves as another racial/ethnic group or as multiracial.

\section{Variables}

The dependent variable, students' reported frequency of QR activities, was a scale derived from four items that asked how often during the current school year students have used numbers, graphs, or statistics to reach conclusions; to analyze an issue; how often they explained numerical information in their writing; and how often they analyzed others' conclusions based on such information (see Table 1 for exact wording and response options). Responses on the four items were averaged together so that the scale scores ranged from one (responded "Never" to all four items) to four (responded "Very often" on all four items). The alpha reliability coefficient for this scale was 0.90 for both first-year and senior students, indicating a high degree of internal consistency. Students' reported frequency of QR activities was not a measure of QR ability. Rather, it represents students' perceptions of how often they engaged in activities that are thought to develop QR skills. During the item-development process, the four QR items were tested in cognitive interviews and focus groups with first-year and senior students to determine whether students were interpreting the items as intended. A confirmatory factor analysis of the four QR items revealed a unidimensional construct and adequate model fit with the data (see Table 7 in Appendix). The factor loadings for the items met conventional standards, ranging from 0.73 to 0.90 (see Table 8 in Appendix).

Among independent variables, student characteristics included gender, raceethnicity (with White as the reference group), age, first-generation status, transfer status, distance education status, and prior academic ability. The extensive research on college students has shown these to be influential factors in college students' experiences and development (Pascarella and Terenzini 2005). A variable that indicated whether a student indicated a major (or expected major) in science, technology, engineering, or mathematics (STEM) was included to 
examine disciplinary effects. Approximately $40 \%$ of first-year and senior students were STEM majors. Students’ prior academic ability was measured by combined verbal and quantitative SAT score. ACT scores were converted to the SAT scale using an ACT-SAT concordance table (ACT 2008). The average combined SAT score for first-year and senior students was 1,151 and 1,144, respectively. Descriptive statistics for all variables used in the study are given in Table 3.

Table 3

Descriptive Statistics

\begin{tabular}{|c|c|c|c|c|c|c|c|c|}
\hline & \multicolumn{4}{|c|}{ First-year Students $(n=7051)$} & \multicolumn{4}{|c|}{ Seniors $(n=6450)$} \\
\hline & \multicolumn{3}{|c|}{ Std. } & \multirow[b]{2}{*}{ Max } & \multicolumn{3}{|c|}{ Std. } & \multirow[b]{2}{*}{ Max } \\
\hline & Mean & Dev. & Min & & Mean & Dev. & Min & \\
\hline Frequency of QR activities & 2.34 & 0.85 & 1 & 4 & 2.53 & 0.89 & 1 & 4 \\
\hline Female & 0.63 & 0.48 & 0 & 1 & 0.60 & 0.49 & 0 & 1 \\
\hline African-American & 0.08 & 0.28 & 0 & 1 & 0.06 & 0.25 & 0 & 1 \\
\hline Asian & 0.07 & 0.25 & 0 & 1 & 0.05 & 0.21 & 0 & 1 \\
\hline Hispanic & 0.06 & 0.24 & 0 & 1 & 0.05 & 0.21 & 0 & 1 \\
\hline White & 0.71 & 0.45 & 0 & 1 & 0.79 & 0.40 & 0 & 1 \\
\hline Other race-ethnicity & 0.07 & 0.26 & 0 & 1 & 0.05 & 0.21 & 0 & 1 \\
\hline SAT score (divided by 100 ) & 11.51 & 1.61 & 5.3 & 16 & 11.44 & 1.70 & 5.1 & 16 \\
\hline First-generation status & 0.32 & 0.47 & 0 & 1 & 0.33 & 0.47 & 0 & 1 \\
\hline Age & 18.54 & 1.57 & 16 & 62 & 22.07 & 2.56 & 18 & 61 \\
\hline Transfer student & 0.04 & 0.20 & 0 & 1 & 0.18 & 0.39 & 0 & 1 \\
\hline Full-time & 0.99 & 0.11 & 0 & 1 & 0.95 & 0.21 & 0 & 1 \\
\hline Distance education student & 0.01 & 0.08 & 0 & 1 & 0.01 & 0.11 & 0 & 1 \\
\hline STEM major & 0.41 & 0.49 & 0 & 1 & 0.38 & 0.49 & 0 & 1 \\
\hline Enrollment size & & & & & & & & \\
\hline (in thousands) & 20.29 & 13.61 & 1.06 & 37.83 & 20.74 & 14.13 & 1.06 & 37.83 \\
\hline Private institution & 0.23 & 0.42 & 0 & 1 & 0.24 & 0.43 & 0 & 1 \\
\hline Institution emphasizes QR & 0.39 & 0.49 & 0 & 1 & 0.32 & 0.47 & 0 & 1 \\
\hline
\end{tabular}

Institutional characteristics examined included enrollment size, institutional control (public/private institution), and institutional emphasis on QR. We initially identified institutions with an emphasis on QR from a list provided by Steen (2007) on his QL Web site and institutions that were featured in Current Practices in Quantitative Literacy (Gillman 2006). In view of the time lag between those sources and our data, we confirmed an institution's emphasis on QR through a review of the institutions' Web sites (carried out in 2012). We searched Web sites for evidence that the institution promoted QR, such as a QR course requirement or a $\mathrm{QR}$ center. Members of the research team conducted the Web site reviews, and then discussed the evidence to reach consensus on whether a QR emphasis was indicated. The ten institutions identified as having an emphasis on QR were those that had at minimum a QR course requirement for all students. All of the institutions in the sample had a math requirement for students, and many of the Web sites expressed a commitment to QR, but if the only course requirement related to $\mathrm{QR}$ was a mathematics course then the institution was not counted as having an emphasis on QR for these purposes. For example, one institution's Web site listed QR as a general education requirement, but it could be filled by taking calculus or college algebra, with no evidence of a course 
specifically geared towards QR. In contrast, an institution that was identified as having an emphasis on QR requires all students to pass a QL assessment exam or a course titled "Introduction to Quantitative Reasoning." In addition to a required QR course, four of the ten identified institutions had a center on campus that provided support for students to develop their quantitative skills in a variety of courses. Some centers also offered support for faculty to integrate QR skills in their courses. All but two of the ten institutions identified in our study as having an emphasis on QR were featured by Steen (2007) and Gillman (2006). A list of institutions and whether or not they were identified as having an emphasis on QR is presented in Table 4.

Table 4

List of institutions and QR Emphasis Status

\begin{tabular}{lc}
\hline Institution & $\begin{array}{c}\text { Emphasis } \\
\text { on QR }\end{array}$ \\
\hline Augsburg College & Yes \\
Bacone College & No \\
DePaul University & Yes \\
DePauw University & Yes \\
Dixie State College of Utah & No \\
Elizabethtown College & No \\
Florida A\&M University & No \\
Florida Southern College & No \\
Hamilton College & Yes \\
Hastings College & No \\
Johnson State College & Yes \\
Juniata College & Yes \\
Manchester College & Yes \\
Mount Ida College & No \\
Penn State University - University Park & No \\
Peru State College & No \\
Shawnee State University & No \\
Texas Tech University & No \\
The Citadel, The Military College of South Carolina & No \\
University at Buffalo, State University of New York & No \\
University of North Carolina Wilmington & Yes \\
University of South Carolina Columbia & No \\
University of Washington Bothell & Yes \\
Virginia Commonwealth University & Yes \\
William Jewell College & No \\
\hline
\end{tabular}

\section{Data Analysis}

Data were analyzed two ways. First, descriptive analyses were conducted exploring student's reported frequency of QR activities across disciplinary categories. Second, multivariate techniques were used to assess the relationship between reported use of QR activities and various student and institutional characteristics. Given the nested structure of our data (students nested within institutions), we used multilevel regression techniques (Raudenbush and Bryk 2002) to explore the relationship between student and institutional characteristics and students' reported frequency of QR activities. Prior to the estimation of the 
multilevel models, preliminary OLS regression analyses were conducted to test for the possibility of differential effects by major grouping (STEM versus nonSTEM). This was done by creating a set of interaction terms, by taking the product of each independent variable (other than STEM) and the indicator variable for STEM major. Then the amount of incremental variance explained by the interaction terms was calculated. The increase in variance explained by the addition of the interaction terms was statistically significant for both first-year $\left(\Delta R^{2}=.004, F(14,7021)=1.883, p=.023\right)$ and senior students $\left(\Delta R^{2}=.006\right.$, $F(14,6420)=3.247, p<.001)$ indicating that the influences of the variables in the model on the frequency of QR activities differed between students majoring in STEM fields and non-STEM fields (Aiken and West 1991; Jaccard and Turrisi 2003). Based on these findings, the final analyses were conducted separately for students majoring in STEM and non-STEM fields. Thus, we ran four separate models for first-year STEM majors, first-year non-STEM majors, senior STEM majors, and senior non-STEM majors. ${ }^{2}$

Limitations. This exploratory study used a very coarse measure of interventions to promote QR - the simple presence or absence of institutional emphasis on QR as inferred from institutional Web sites. It is likely that, as with many other reforms, the fine details of implementation matter. From our Web site review, the emphasis institutions appeared to place on QR varied greatly. Some institutions had comprehensive and detailed programs where QR was integrated in a variety of courses across the curriculum, while other institutions had a one-course QR requirement for all students. In addition to course requirements, some institutions offered a QR support center for students or faculty. In addition to the coarse nature of the measure, basing the judgment of a QR emphasis on a review of institutional Web sites is subject to error. QR emphasis may be insufficiently documented on a Web site; we may have failed to locate relevant information; or the information gleaned from our 2012 review may not reflect an institution's QR emphasis in 2011.

The dependent variable, students' reported frequency of QR activities, is not a direct measure of students' exposure to QR. Future research could explore other ways to investigate students' exposure to QR. This could be done through direct observation, an examination of course syllabi, or through interviews with faculty members. While students' perceptions may not be a direct measure of a students' involvement in $\mathrm{QR}$, it offers institutions an additional tool to assess the

\footnotetext{
${ }^{2}$ We analyze first-year and senior students separately given the different educational experiences between first-year and senior students. Most significantly for our study, first-year students are typically enrolled in general education coursework, while seniors are typically enrolled in their major coursework.
} 
opportunities they offer students to develop these important skills and can be viewed as complementary to other direct measures of QR activity and ability.

With these limitations in mind, this study presents a valuable first step in investigating the factors related to QR activities among college students.

\section{Results}

Results for the four multilevel regression analyses are given in Table 5. We consider these results relative to the research questions stated earlier in this article. Because we estimated separate models for STEM and non-STEM majors, we consider the first two questions together.

Table 5

Regression Results $^{\mathrm{a}}$

\begin{tabular}{|c|c|c|c|c|}
\hline & \multicolumn{2}{|c|}{ First-Year } & \multicolumn{2}{|c|}{ Senior } \\
\hline & STEM & Non-STEM & STEM & Non-STEM \\
\hline \multirow[t]{2}{*}{ Intercept } & $2.554 * * *$ & $2.159 * * *$ & $2.794 * * *$ & $2.357 * * *$ \\
\hline & $(0.038)$ & $(0.026)$ & $(0.044)$ & $(0.023)$ \\
\hline \multirow[t]{2}{*}{ Female } & $-0.177^{* * *}$ & $-0.253^{* * *}$ & $-0.266^{* * *}$ & $-0.231^{* * *}$ \\
\hline & $(0.033)$ & $(0.021)$ & $(0.030)$ & $(0.026)$ \\
\hline \multirow[t]{2}{*}{ African-American } & -0.030 & 0.028 & -0.050 & $0.150 *$ \\
\hline & $(0.044)$ & $(0.113)$ & $(0.077)$ & $(0.074)$ \\
\hline \multirow[t]{2}{*}{ Asian } & $0.126^{*}$ & $0.089 *$ & 0.055 & $0.181^{* *}$ \\
\hline & $(0.057)$ & $(0.036)$ & $(0.048)$ & $(0.064)$ \\
\hline \multirow[t]{2}{*}{ Hispanic } & -0.034 & -0.034 & 0.084 & 0.033 \\
\hline & $(0.080)$ & $(0.057)$ & $(0.080)$ & $(0.048)$ \\
\hline \multirow[t]{2}{*}{ Other race-ethnicity } & 0.161 & 0.125 & -0.068 & $0.192 * *$ \\
\hline & $(0.090)$ & $(0.080)$ & $(0.070)$ & $(0.064)$ \\
\hline \multirow[t]{2}{*}{ SAT score (divided by 100) } & 0.013 & $-0.035^{* * *}$ & 0.019 & -0.014 \\
\hline & $(0.011)$ & $(0.010)$ & $(0.012)$ & $(0.010)$ \\
\hline \multirow[t]{2}{*}{ First-generation status } & 0.037 & 0.013 & -0.034 & $0.105^{* *}$ \\
\hline & $(0.069)$ & $(0.027)$ & $(0.042)$ & $(0.037)$ \\
\hline \multirow[t]{2}{*}{ Age } & 0.001 & -0.008 & -0.004 & $-0.013 * *$ \\
\hline & $(0.013)$ & $(0.005)$ & $(0.006)$ & $(0.004)$ \\
\hline \multirow[t]{2}{*}{ Transfer student } & 0.031 & 0.049 & -0.034 & 0.034 \\
\hline & $(0.080)$ & $(0.076)$ & $(0.04)$ & $(0.030)$ \\
\hline \multirow[t]{2}{*}{ Full-time } & 0.025 & 0.160 & $0.255^{* *}$ & $0.115^{*}$ \\
\hline & $(0.223)$ & $(0.091)$ & $(0.073)$ & $(0.054)$ \\
\hline \multirow[t]{2}{*}{ Distance education student } & 0.103 & -0.008 & 0.130 & 0.164 \\
\hline & $(0.179)$ & $(0.137)$ & $(0.121)$ & $(0.147)$ \\
\hline Institutional enrollment size & -0.002 & $0.006 *$ & -0.0004 & 0.002 \\
\hline (in thousands) & $(0.003)$ & $(0.003)$ & $(0.004)$ & $(0.002)$ \\
\hline \multirow[t]{2}{*}{ Private institution } & 0.092 & 0.047 & -0.007 & 0.068 \\
\hline & $(0.08)$ & $(0.075)$ & $(0.121)$ & $(0.069)$ \\
\hline \multirow[t]{2}{*}{ Institution emphasizes QR } & 0.069 & $0.132 *$ & 0.188 & 0.037 \\
\hline & $(0.075)$ & $(0.051)$ & $(0.097)$ & $(0.049)$ \\
\hline Intraclass correlation & .035 & .015 & .050 & .012 \\
\hline Variance explained at the student-level & 012 & .024 & .028 & .023 \\
\hline Variance explained at the institution-level & 315 & 290 & 242 & 286 \\
\hline $\begin{array}{l}\text { a Standard errors given in parentheses } \\
{ }^{*} p<.05 ; * * p<.01 ; * * * p<.001\end{array}$ & & & & \\
\hline
\end{tabular}


1. What is the relationship between student and institution characteristics and QR?

2. Are the influences the same for STEM and Non-STEM majors?

In all four models, gender had a statistically significant relationship with students' use of QR activities. After controlling for the other variables in the model, males tend to report more-frequent QR activities than their female counterparts. Significant racial-ethnic differences were also found. The effect for Asians was statistically significant in all models except the model for senior STEM majors, indicating that Asian students tend to report more-frequent QR activities than White students, net of the other variables in the model. The effect for African-Americans was significant in the senior non-STEM model, indicating that for this subgroup, African-Americans report more-frequent QR activities than White students. SAT/ACT score had a modest negative relationship with QR activities for first-year non-STEM majors. Thus, non-STEM first-year students with lower average SAT/ACT scores tend to report more-frequent QR activities than their peers with higher scores. First-generation status and age were both positively related to frequency of QR activities for senior non-STEM majors. Full-time seniors in both STEM and non-STEM fields engaged more in QR activities than otherwise similar part-time seniors.

With regard to institutional characteristics, enrollment size and institutional emphasis on QR had a significant positive relationship with frequency of QR activities for first-year non-STEM majors. First-year non-STEM majors attending larger institutions tended to report greater frequency of QR activities than their counterparts attending smaller institutions.

3: Do students at institutions with a QR emphasis report more QR activities?

First-year non-STEM majors at institutions that emphasize QR report greater frequency of QR activities. Our results show no evidence of a QR-emphasis effect for senior non-STEM majors, however. Nor did we find evidence of a QRemphasis effect for STEM majors.

\section{Discussion}

These analyses document some interesting sources of variability in the reported frequency of QR activities at a diverse set of four-year colleges and universities. As would be expected, both first-year and senior students in STEM fields reported more-frequent use of QR activities than students majoring in non-STEM fields. As shown in Figure 1, first-year and senior students majoring in engineering, physical sciences, and biological sciences reported the most-frequent use of QR activities while education and arts and humanities majors reported the lowest 
frequency of QR activities. In fact, first-year STEM majors reported almost twofifths of a standard deviation (Cohen's $d=.37)^{3}$ more-frequent QR activities than non-STEM majors, and senior STEM majors report almost half a standard deviation (Cohen's $d=.49$ ) more-frequent QR activities than non-STEM majors. The greater frequency of $\mathrm{QR}$ activities is hardly surprising, of course. At a minimum, it offers some validity evidence for the QR measures used in this study.

Among most majors, Figure 1 shows seniors to have higher levels of QRactivity frequency than first-year students. The exception appears to be the two groups that show the lowest frequency at either level: education and arts and humanities majors, among whom seniors report about the same frequency of QR activities as their first-year peers. This suggests that students in these majors have a lower exposure to QR throughout their undergraduate studies.

Not only does majoring in a STEM discipline appear to affect the frequency of QR activities, the influences of several variables examined on reported QR activity differed between STEM and non-STEM majors. These findings suggest the need for individual colleges and universities to focus their efforts on better understanding who in fact is being exposed to QR activities, especially in nonSTEM disciplines like education and arts and humanities.

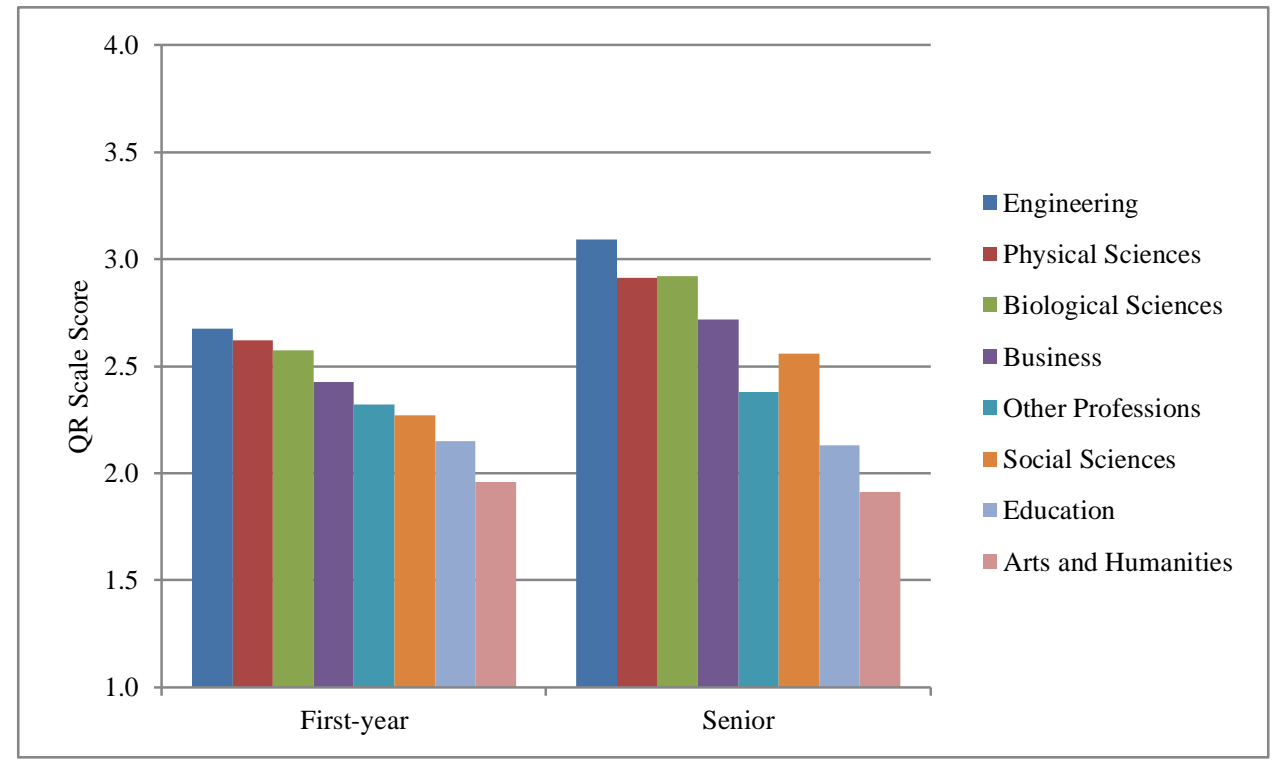

Figure 1. Average Frequency of QR Activities by Class Level and Major Category

A welcome finding in these analyses is the absence of a relationship between frequency of QR activities and measured cognitive ability as captured by SAT/ACT scores for seniors and first-year STEM majors, net of the other

\footnotetext{
${ }^{3}$ Cohen's $d$ effect sizes are reported for statistically significant $(\mathrm{p}<.05)$ pairwise differences.
} 
variables in our models. This suggests that prior preparation and achievement do not pose a major obstacle to efforts to broadening students' exposure to QR activities. Interestingly, the effect for first-year non-STEM majors is negative indicating that students with lower prior academic achievement tend to report more-frequent QR activities than similar peers with higher scores. This finding may be indicative of lower-ability students' participation in developmental education in mathematics. It may also be that students with lower admissions test scores need to spend more time on these activities, and this is reflected in their perceptions of frequency of behavior.

Female students showed a consistently lower exposure to QR than males in all four models even after controlling for other demographic characteristics, measured cognitive ability, and institutional characteristics. This is consistent with the findings from NAAL which demonstrated that females tend to have lower average QL abilities. Furthermore, the gender gap between males and females ranged about 0.2 units on the QR scale, net of the other variables in the model (see adjusted means for gender in Table 6). While the gender gap was apparent in all four models, this could be related to differences in the gender composition of the various majors aggregated together as STEM and non-STEM majors, which themselves may vary in the degree of emphasis on QR activities. For example, women make up a much larger share of biological sciences majors than engineering majors (NSSE 2011), and, as shown in Figure 1, QR activities were most frequent among engineering majors. However, when we examine gender differences within major categories we still find a substantial gender gap. For instance, first-year male students majoring in education, social sciences, other professions (i.e., not business or engineering), and arts and humanities report about three tenths of a standard deviation more frequent QR activity than their female counterparts (Cohen's $d=.35, d=.29, d=.29, d=.28$, respectively). More research is needed to more fully explore these gender disparities.

Table 6

Adjusted QR Scores by Gender

\begin{tabular}{lrrrrr}
\hline & \multicolumn{2}{c}{ First-Year } & & \multicolumn{2}{c}{ Senior } \\
\cline { 2 - 3 } \cline { 5 - 6 } & STEM & Non-STEM & & STEM & Non-STEM \\
\hline Males & 2.66 & 2.32 & & 2.93 & 2.50 \\
Females & 2.48 & 2.07 & & 2.67 & 2.27 \\
\hline
\end{tabular}

We also found QR activity to differ by race-ethnicity. While we found no differences between African-Americans and Whites or between Hispanics and Whites for first-year students, Asian first-year students - whether or not they were STEM majors-reported more-frequent QR activities than Whites, even after controlling for other student and institutional characteristics. Racial-ethnic differences were also found for senior, non-STEM majors, among whom Asians 
and African-Americans reported more-frequent QR activities than Whites. Despite these differences, results for senior STEM majors showed no evidence of differences between Whites and African-Americans, Asians, or Hispanics. Thus among seniors, QR activity in STEM disciplines does not appear to vary with respect to race-ethnicity. While findings from the 2003 NAAL (Kutner et al. 2007) demonstrated racial-ethnic differences in QL, the same patterns were not reflected in the frequency of college-level QR activities. Nevertheless, these findings raise some interesting questions about why racial-ethnic differences are present for some majors and not others. Here again, one possible explanation is that these groups are differentially clustered in non-STEM majors which themselves differ in QR-activity frequency as shown in Figure 1.

We found enrollment size to have a relationship with first-year students' reported use of QR activities, but only among non-STEM majors. This effect was net of controls for institutional emphasis on QR. The larger the institution, the more frequently first-year non-STEM students reported using numerical, graphical, and statistical information. What is it about larger institutions that accounts for the more frequent use of QR activities among non-STEM first-year students? It is possible that the mix of non-STEM majors is different at smaller institutions (e.g., more majors in the arts \& humanities). Another possibility is that larger institutions are more likely to have first-year general education programs that involve QR skills (e.g., a mathematic requirement). These possibilities call for further investigation with a larger institutional sample that would permit more detailed specification of institutional differences.

Institutional emphasis on QR appears to promote exposure to QR activities, especially for first-year students and students in non-STEM disciplines. Results from the regression analyses demonstrate that after controlling for pre-college ability and other student and institutional characteristics, first-year non-STEM majors at institutions with an emphasis on QR reported significantly greater frequency of QR activity. That said, the magnitude of the effect of QR emphasis was quite modest (standardized regression coefficient for QR emphasis is .08). On the other hand, four of the five institutions with the highest average first-year QR scores were identified as having an emphasis on QR. Further exploration revealed that three of the top five institutions with the highest average QR scores for firstyear arts and humanities majors had a QR requirement for all students. This is of particular interest because arts and humanities majors may be most in need of such programs because their curricula typically do not emphasize QR activities. These findings call attention to the likely variability in the fine details of what we call a QR emphasis, and they offer indirect evidence in favor of more-aggressive efforts to ensure that all students have opportunities to develop QR skills. 


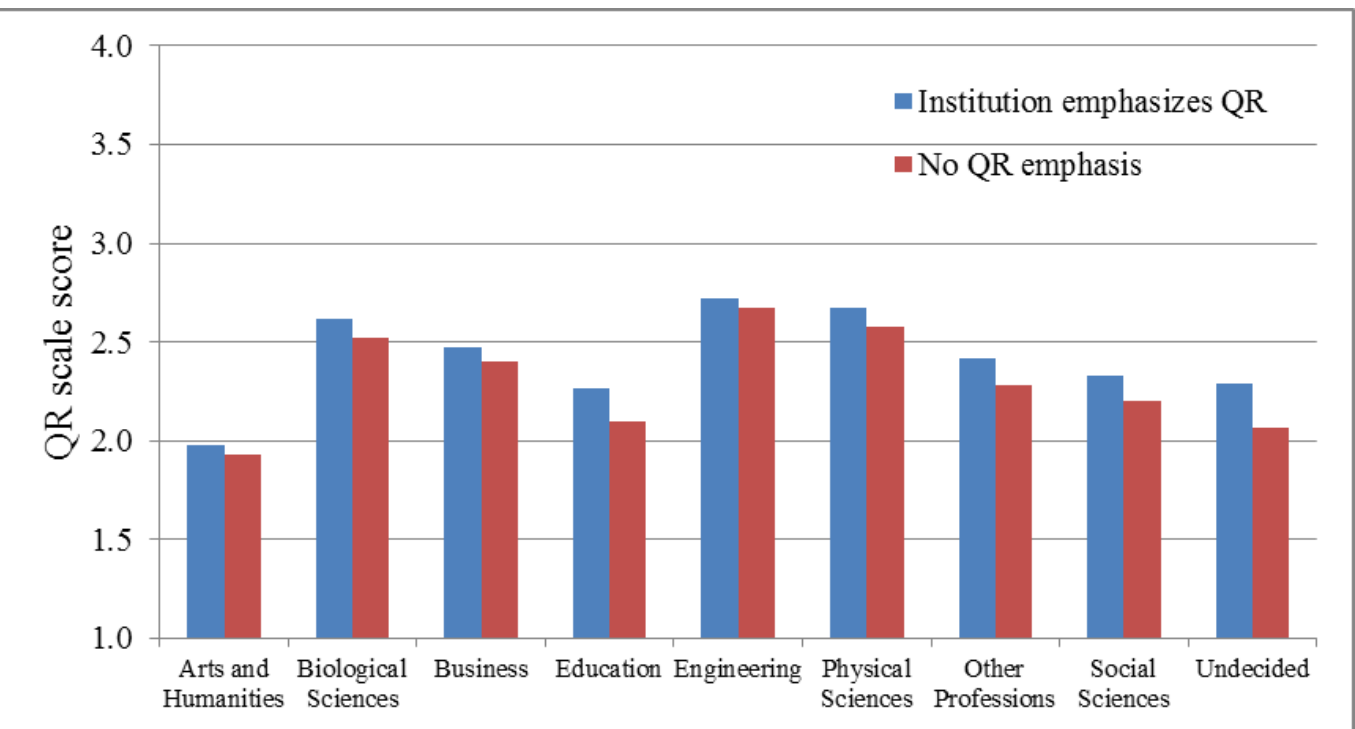

Figure 2. Average Frequency of QR for First-year Students by QR Emphasis

First-year students in most disciplines at institutions with an emphasis on QR reported more frequent QR activity (Fig. 2). In fact, undecided first-year students attending institutions with an emphasis on QR report almost three tenths of a standard deviation (Cohen's $d=.28$ ) more frequent QR activities than their counterparts at institutions that do not emphasize QR. Moreover, first-year education, social science, and other professional students at institutions with an emphasis on QR had almost a fifth of standard deviation (Cohen's $d=.20, d=.16$, and $d=.15$, respectively) more-frequent QR activity than their counterparts at institutions without a QR emphasis. Overall, these results suggest that incorporating a QR course requirement (a criterion for our QR emphasis measure) may be an effective way for institutions to increase the amount of QR activities for first-year students in all majors, but particularly for those in non-STEM fields. On the other hand, we found no evidence that institutional emphasis on QR impacts the frequency of QR activities for seniors (whether STEM majors or not). This could reflect the fact the most QR programs are geared towards first-year students and suggests that the impact on first-year non-STEM students may be due to the presence of a course requirement (which would normally be satisfied early in a student's career).

There may be other important variables not included that impact students' frequency of QR activities, and the relatively small proportion of variance explained by the regression models suggests this is the case. The low proportion of variance explained is not completely a surprise given that other studies have also shown that background characteristics explain relatively little variation in student engagement measures (Pike 2004; Brint et al. 2012). Future studies should 
investigate what drives the variation in students' reported use of QR activities. For first-year students, a more systematic accounting of general education requirements would likely improve the proportion of variance explained. Other factors besides major — such as medical school intentions-could help to explain variation in QR activities. For seniors, because STEM fields vary in their everyday use of quantitative methods, a finer-grained measure of students' majors would also improve the model by affording a more in-depth examination of disciplinary differences in students' use of QR activities. Also, this study only used information for the first major reported. Incorporating information about a second major might also improve the model's explanatory power. Although the student and institutional characteristics employed in this study explained a relatively small fraction of the variability in reported frequency of QR activities, better understanding the relationship between these variables and QR is important especially given that national assessments have found gender and race-ethnicity differences in QL (Kutner et al. 2007).

\section{Conclusions}

This exploratory study is but a first step in investigating students' use of QR activities. Still, our findings present an interesting glimpse into college students' participation in QR activities. We were interested in the relationship between frequency of QR activities and various student and institutional characteristics and found that QR activities were indeed related to several student and institutional characteristics, even when examining STEM and non-STEM majors separately. Additionally, we observed that the impact of these characteristics were different for STEM and non-STEM majors. We also found that institutional emphasis on QR was positively related to first-year students' use of QR skills, especially among students majoring in non-STEM disciplines. This finding is promising in that institutional policies may indeed have an influence on students' use of QR especially for non-STEM majors who are most at risk for not developing these skills.

Not only do these findings present a first glimpse into students' use of QR activities in college, they also raise interesting questions for future research. More research is needed to investigate the link between involvement in QR activities and actual QR abilities. Additional research also needs to explore how various forms of institutional QR emphasis-such as the presence of QR centers on campus and whether they provide services for faculty as well as studentsimpacts students' experiences with QR. We also need more detailed analyses on the effectiveness of various QR programs such as QR course requirements versus a QR-across-the-curriculum approach versus a combination of both. Studies could also investigate how engagement in QR relates to outcomes such as GPA, 
retention, or critical thinking skills. Additional studies could also explore faculty views of QR and how they structure their courses so students learn these important skills. This may be particularly important among faculty in education and arts and humanities, where our results suggest that QR experiences are consistently the lowest. Indeed, these are the two disciplinary groups that showed no noteworthy increase in QR activities among seniors relative to first-year students.

These findings suggest value in explicitly assessing college students' exposure to QR activities. Furthermore, they suggest possible avenues for additional inquiry into the specific curricular and co-curricular features that most effectively promote the development of QR skills. Hopefully, this will also lead to more programs geared towards students that are at risk for not developing these skills, particularly in non-STEM fields such as education and arts and humanities.

With the growing use of quantitative information in the workplace and in everyday life, as well as the importance of QL for effective democratic participation, it is essential that all college students-not just STEM majorsdevelop facility in QR. Increased exposure to QR activities across all majors is necessary to achieve this important goal. Results of this study suggest that certain students may be at greater risk for not developing these important skills, especially women and students majoring in non-STEM disciplines. These findings also provide evidence for a modest positive impact of a QR course requirement for all students. College and university faculty might use these results to begin conversations about targeting interventions for those at risk of not developing the QR skills necessary to succeed in this increasingly quantitative world.

\section{References}

ACT. 2008. ACT-SAT Concordance. http://www.act.org/aap/concordance/pdf/reference.pdf (accessed October 16, 2011).

Aiken, L. S., and West, S. G. (1991). Multiple regression: Testing and interpreting interactions. Newbury Park, CA: Sage.

Association of American Colleges and Universities. 2007. College learning for the new global century: A report from the National Leadership Council for Liberal Education and America's Promise. http://www.aacu.org/leap/documents/GlobalCentury_final.pdf (accessed April 10, 2012).

- 2009. Quantitative literacy VALUE rubric. http://www.aacu.org/value/rubrics/pdf/QuantitativeLiteracy.pdf (accessed April 10, 2012).

Astin, A. W. 1984. Student involvement: A development theory for higher education. Journal of College Student Development. 25 (4): 297-308. 
-1993. What matters in college? Four critical years revisited. San Francisco: Jossey-Bass.

Brint, S., A. M. Cantwell, and P. Saxena. 2012. Disciplinary categories, majors, and undergraduate academic experiences: Rethinking Bok’s “Underachieving Colleges" thesis. Research in Higher Education. 53 (1): 1-25. http://dx.doi.org/10.1007/s11162-011-9227-2

Dingman, S. W., and B. L. Madison. 2010. Quantitative reasoning in the contemporary world, 1: The course and its challenges. Numeracy, 3 (2): Article 4. http://dx.doi.org/10.5038/1936-4660.3.2.4 (accessed October 16, 2011). and B. L. Madison. 2011. Twenty-first-century quantitative education: Beyond content. Peer Review, 13 (3): 15-18. http://www.aacu.org/peerreview/pr-SU11/DingmanMadison.cfm (accessed October 14, 2011).

Gillman, R., ed. 2006. Current practices in quantitative literacy. Washington, D.C.: Mathematics Association of America.

Jaccard, J., and R. Turrisi. 2003. Interaction effects in multiple regression. Thousand Oaks, CA: Sage Publications.

Kuh, G. D. 2001. Assessing what really matters to student learning: Inside the National Survey of Student Engagement. Change. 33 (3): 10-17. http://dx.doi.org/10.1080/00091380109601795

- 2009. The National Survey of Student Engagement: Conceptual and empirical foundations. In R. Gonyea \& G. D. Kuh, eds., New Directions for Institutional Research: Using student engagement data in institutional research. vol. 141:5-20. San Francisco: Jossey-Bass. http://dx.doi.org/10.1002/ir.283

—, J. H. Schuh, E. J. Whitt, and Associates. 1991. Involving colleges: Successful approaches to fostering student learning and development outside the classroom. San Francisco: Jossey-Bass.

Kutner, M., E. Greenburg, Y. Jin, B. Boyle, Y. Hsu, and E. Dunleavy. 2007. Literacy in everyday life: Results from the 2003 National Assessment of Adult Literacy. Washington, D.C.: U.S. Department of Education, National Center for Educational Statistics (NCES 2007-480).

Madison, B. L. 2009. All the more reason for QR across the curriculum. Numeracy, 2 (1): Article 1. http://dx.doi.org/10.5038/1936-4660.2.1.1 (accessed October 16, 2011).

- and L. A. Steen, eds. 2003. Quantitative literacy: Why numeracy matters for schools and colleges. Princeton, NJ: National Council of Education and the Disciplines.

— and L. A. Steen, eds. 2008. Calculation vs. context: Quantitative literacy and its implications for teacher education. Racine, WI: Mathematics Association of America.

McCormick, A. C., J. Kinzie, and R. M. Gonyea. 2013. Student engagement: Bridging research and practice to improve the quality of undergraduate education. In M. B. Paulsen, ed., Higher education: Handbook of theory and research, vol. 28: 4792. Dordrecht, The Netherlands: Springer. 
McDonald, R. P., and M. R. Ho. 2002. Principles and practice in reporting structural equation analyses. Psychological Methods, 7 (1): 64-82.

National Commission on Excellence in Education. 1983. A nation at risk: The imperative for education reform. Washington, DC: U.S. Department of Education.

National Council of Teacher of Mathematics. 1989. Curriculum and evaluation standards for school mathematics. Reston, VA: National Council of Teacher of Mathematics.

- 2000. Principles and standards for school mathematics. Reston, VA: National Council of Teacher of Mathematics.

National Research Council. 1989. Everybody counts: A report to the nation on the future of mathematics education. Washington, DC: National Academies Press.

National Survey of Student Engagement. 2011. Frequencies by gender. http://nsse.iub.edu/html/summary tables.cfm (accessed April 30, 2012).

Pace, C. R. 1979. Measuring outcomes of college: Fifty years of findings and recommendations for the future. San Francisco: Jossey-Bass.

Pascarella, E. T. 1985. College environmental influences on learning and cognitive development: A critical review of syntheses. In J. Smart, ed., Higher education: Handbook of theory and research, vol. 1: 1-64. New York: Agathon.

_ and P. T. Terenzini. 1991. How college affects students: Findings and insights from twenty years of research. San Francisco: Jossey-Bass.

— and P. T. Terenzini. 2005. How college affects students: A third decade of research. San Francisco: Jossey-Bass.

Pike, G. R. 2004. Measuring quality: A comparison of "US News” rankings and NSSE benchmarks. Research in Higher Education. 45 (2): 193-208. http://dx.doi.org/10.1023/B:RIHE.0000015695.84207.44

Pike, G. R., G. D. Kuh, and R. M. Gonyea. 2003. The relationship between institutional mission and students' involvement and educational outcomes. Research in Higher Education. 44 (2): 241-261. http://dx.doi.org/10.1023/A:1022055829783

Raudenbush, S. W., and A. S. Bryk. 2002. Hierarchical linear models: Applications and data analysis methods, second edition. Thousand Oaks, CA: Sage Publications.

Rivera-Batiz, F. L. 1992. Quantitative literacy and the likelihood of employment among young adults in the United States. The Journal of Human Resources, 27 (2): 313-328. http://dx.doi.org/10.2307/145737

Shavelson, R. J. 2008. Reflections on quantitative reasoning: An assessment perspective. In B. L. Madison and L. A. Steen, eds. Calculation vs. context: Quantitative literacy and its implications for teacher education. Racine, WI: Mathematics Association of America.

Schneider, C. G. 2004. Setting greater expectations for quantitative learning. Peer Review, Summer 2004: 26-27.

Schreiber, J. B., F. K. Stage, J. King, A. Nora, and E. A. Barlow. 2006. Reporting 
structural equation modeling and confirmatory factor analysis results: A review. The Journal of Educational Research, 99 (6): 323-337. http://dx.doi.org/10.3200/JOER.99.6.323-338

Steen, L. A., ed. 1997. Why numbers count: Quantitative literacy for tomorrow's America. New York: College Entrance Examination Board. 2001. Mathematics and democracy: The case for quantitative literacy. Princeton, NY: Woodrow Wilson National Fellowship Foundation. 2007. Selected quantitative literacy programs in U.S. colleges and universities.

http://web.archive.org/web/20100808200728/http:/www.stolaf.edu/people/steen/ Papers/qlprogs.pdf (accessed April 20, 2012).

Taylor, C. 2008. Preparing students for the business of the real (and highly quantitative) world. In B. L. Madison and L. A. Steen, eds. Calculation vs. context: Quantitative literacy and its implications for teacher education. Racine, WI: Mathematics Association of America.

Wilkins, J. L. M. 2000. Preparing for the $21^{\text {st }}$ century: The status of quantitative literacy in the United States. School Science and Mathematics, 100 (8): 406-418. http://dx.doi.org/10.1111/j.1949-8594.2000.tb17329.x

- 2010. Modeling quantitative literacy. Educational and Psychological Measurement, 70 (2): 1-24. http://dx.doi.org/10.1177/0013164409344506

\section{Appendix: Confirmatory Factor Analysis Results}

The following tables provide model fit statistics and factor loadings from the confirmatory factor analysis of the four QR items for both first-year and senior students.

Table 7

Confirmatory factor analysis: Model-fit results

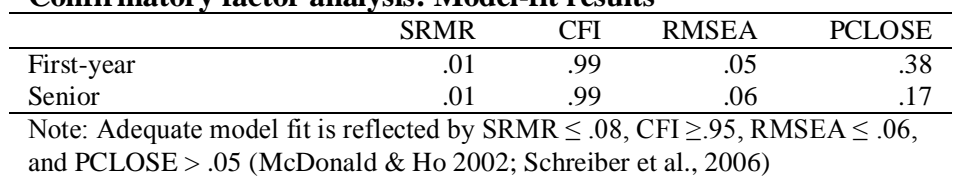

Table 8

Items, CFA factor loadings, and Cronbach's alphas for first-year and senior students

\begin{tabular}{lrr}
\hline & \multicolumn{2}{c}{ Factor loading } \\
\cline { 2 - 3 } Item & First-year & Senior \\
\hline Reached conclusions based on your own analysis of numbers, graphs, or statistics & .73 & .77 \\
Used numbers, graphs, or statistics to help analyze a contemporary or historical issue & .78 & .77 \\
(poverty, climate change, etc.) & .88 & .90 \\
Explained in writing the meaning of numbers, graphs, or statistics & .90 & .88 \\
\hline Analyzed others' conclusions by using numbers, graphs, or statistics & & .90 \\
\hline
\end{tabular}

